\title{
NEW TECHNOLOGY ADOPTION: EMBRACING CULTURAL INFLUENCES
}

\author{
Debra J. Borkovich, Robert Morris University, borkovich@rmu.edu \\ Jennifer Breese-Vitelli, Middle GA State University, jennifer.breese-vitelli@mga.edu \\ Robert Joseph Skovira, Robert Morris University, skovira@rmu.edu
}

\begin{abstract}
This paper presents a pragmatic approach to understanding how and why organizational culture influences the successful adoption of new technology. In order to maintain a competitive global position in an increasingly borderless virtual society, non-profit and for-profit organizations face critical problem-solving and decision-making dilemmas whether to convert current enterprise systems to new innovative technologies, to modify, upgrade, or enhance existing technologies, or to maintain the status quo while awaiting the next product diffusion even more agile, powerful, all-encompassing, and cutting-edge. Through the lens of secondary literature, the reader is led through a series of phases, processes, and roles while examining the potential successes and pitfalls of technology selection and implementation. This research then tests and demonstrates the relevance of organizational culture's influence on the phases of technology adoption and acceptance within a $21^{\text {st }}$ century digital environment.
\end{abstract}

Keywords: Agility, Change Management, Organizational Culture, Technology Adoption, Implementation Processes, Project Management

\section{INTRODUCTION}

Technological innovation drives the world within our social-cultural environments as we know and experience them. But how do we decide which technologies we need and when, and why do we need some of them but not all of them? Many theorists have tried to make sense of the insatiable human need for innovation and progress. In the "Third Wave," Toffler [51] linked and labeled this natural progression of mankind in terms of waves, the first stage beginning with the transition of hunter-gatherers into farmers, or Agrarian Age; through the second stage known as the Industrial Revolution (manufacturing environment); and finally to the current stage, the Information Age, a service-driven knowledge-based society. Debons [17] cleverly paraphrased Toffler's three waves with the phrase, "farms, factories, and floppies," confirming that no matter what moniker man applies, technological innovation has always been a societal norm.

Beniger's [5] detailed history of the rise of technologies argued that exceptional times and situational events force controversy resulting in innovation. Standage [42] cited the great inventions of the industrial revolution as precipitous events for their historical importance; followed by weaponry advancements propagated through world wars; and the subsequent 'cold war' that realized the digital age. Drucker [18] predicted the demise of the manufacturing culture by coining the term, knowledge worker; while Carr [8] argued that the process, not the technology, had the advantage. Christensen's [10] theory of disruptive technology argued that implementation and adoption success is grounded in conflict resolution and change management. Shirky [41] stated: "Revolution does not happen when society adopts new technology, it happens when society adopts new behaviors."

In the second half of the $20^{\text {th }}$ century, the introduction of the digital era and the spawning of bits, mainframe computers and more, the business world began its metamorphose from a blue-collar labor-driven manufacturing society to a white-collar service-oriented society. By the dawning of the nascent $21^{\text {st }}$ century, the transformation was all but complete, with the exception of a few Luddites [42] and outliers. Professionals were demanded to assume technology leadership roles, universities developed degrees and certification programs, and corporations transferred engineers and scientists, among others, into positions of information systems and technology professionals, management theorists, and corporate anthropologists to understand the culture.

Today, we make individual day-to-day technology decisions that significantly impact our success in the world. But who makes these technological decisions for others, specifically in the workplace, and how are these decisions made? These are lofty goals to explore and the information and resources are too vast to be fully considered within 
the confines of this essay. Therefore, the intent of this paper is not to solve the overarching technology adoption crises of today as that philosophical agenda will be left to the theorists. The uniqueness of our paper is the synthesis of social-cultural influences upon the success or failure of organizational technology adoption by applying and interpreting the theories of corporate anthropologists, sociologists, and business management subject matter experts.

Table 1. Incorporating Social-Cultural Influences into the Phases of Technology Adoption

\begin{tabular}{|ll|ll|}
\hline \multicolumn{1}{|c|}{ Phases of Technology Adoption } & & \multicolumn{1}{c|}{ Social-Cultural Influences } \\
\hline - & Understanding the Organizational Culture & $\bullet$ & Meanings, Values, Rituals, Symbols, Practices, Language \\
\hline - & Defining the Leader's Role (CIO) & $\bullet$ & Agent of change \& cultural evolution \\
\hline - & Communicating the Message & $\bullet$ & Medium is the message; Context \\
\hline - & Selecting the Project Manager, Team \& Plan & $\bullet$ & Leaders, Heroes, Champions, Sponsors \\
\hline - & Choosing the Right Technology & $\bullet$ & Necessary upheaval to organizational culture \\
\hline - & Designing the System & - & Agile, iterative, development; Align to Bus. Goals \\
\hline - & Implementing the Process (Checks \& Balances) & $\bullet$ & Change management \& conflict resolution \\
\hline - & Introducing the Technology (Roll-Out) & $\bullet$ & Surviving culture shock \\
\hline
\end{tabular}

For the purposes of this paper, Table 1 depicts the key phases, tasks, and roles that influence the outcome of an innovative technology implementation. Furthermore, we argue that organizational culture has a definitive influence in every phase related to technology adoption. Our paper explores why and how a new technology should be introduced, implemented, and adopted, by limiting the focus to a time and space constrained social-cultural environment, the organizational workplace.

\section{RESEARCH METHODOLOGY}

This paper is framed as a secondary review of technology adoption literature (control factor) and the application of social-cultural literature to a group's organizational behavior (wildcard) to understand the success or failure of technology projects. This methodology provided a means to form critical interpretations and insights without involving the typical qualitative inter-subjective relationships between the actual researchers and the researched. Furthermore, this approach is similar to the impetus behind the secondary analysis of quantitative data [36]. Various arguments in favor of secondary analysis of qualitative data [38, 45, 47] proffer that it can be used to generate new knowledge and hypotheses, support for existing theories; and inform new perspectives or conceptualizations. Our objective was to investigate the relevance of organizational culture upon technology adoption.

Therefore, this research focused on the following hypotheses (Hs):

H1: Organizational culture influences the success or failure of technology adoption in the workplace.

H2: Understanding and incorporating organizational culture into the technology implementation process favorably increases successful technology adoption.

To test our hypotheses, eight phases of technology adoption (Table 1) are examined and compared to organizational social-cultural theories of corporate anthropologists, business management experts, and other social scientists.

\section{THE CULTURE}

The mission of technological innovation has always been to collect the data assets of the organization and structure them in a way that is useful to problem-solvers and decision-makers [13]. However, management research has long suggested that to facilitate decision support, the organizational culture needs to align with the goals and objectives of the enterprise and business intelligence strategy, for without this "cultural glue that welds managers [and employees] together for the implementation of organizational strategies, the absence of this glue would bring about disastrous effects" [44]. Researchers argue that organizational culture is inured and employees tend to embrace information systems that are in concert with their culture and resist those that conflict [11]. However, managements drive new introductions, modifications, upgrades, and enhancements to its business enterprise architecture to pursue economic 
growth, return on investment, increased competitive edge and market share, often without regard to the impact and toll these changes impose upon the cultures and subcultures of its organizational environments.

Companies with strong cultures are healthy because they tolerate and encompass differences [16]. In a mature company, subcultures may disagree with each other but these clashes promote healthy tension and debate. Strong organizational cultures can adapt to diverse and changing circumstances by digging deep into their shared values and beliefs because mutual dependencies of employers and employees require a cultural milieu that benefits all [15]. Figure 1 depicts a strong organizational culture and subcultures where normal barriers and resistance to technological change are gently relaxed over a reasonable time period.

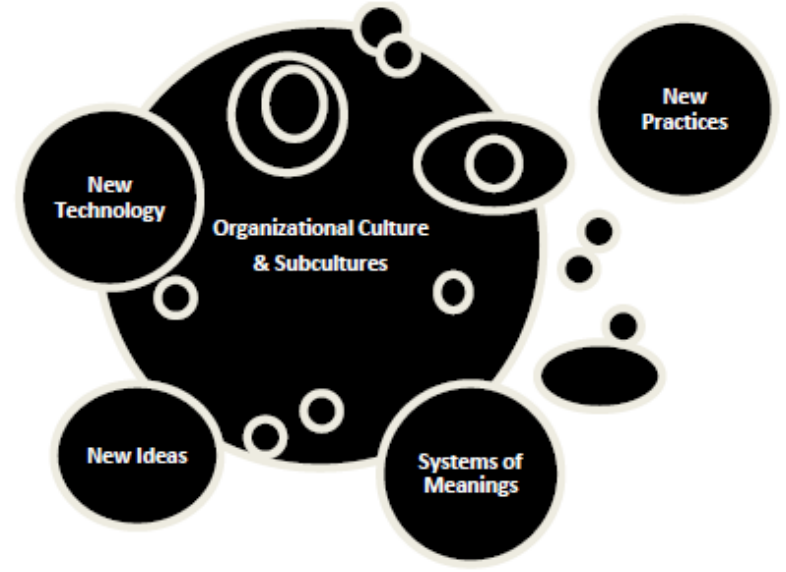

Figure 1. Organizational Technology Acceptance Model

A strong mature organizational culture will eventually lower its barriers to accept new technology, ideas, and practices when they align with the existing business culture.

The influence of corporate culture's impact upon the successful adoption of a technology cannot be diminished. Many anthropologists, sociologists, and technologists concur that the construct of culture equally applies to organizational management and technology implementation. Breslin [7] reports that "having the right set of soft skills is just as important, if not more important, than technical skills and knowledge." Zheng, Yang, and McLean [54] add that "Organizational culture does not directly lend its influence on organizational effectiveness; rather it exerts its influence through shaping the behavior of organizational members." Without organizational meanings and understandings, culture has no purpose; and without culture, organizations have neither meanings nor understandings. Geertz [22] avers that: "Culture is public because meaning is."

"Decisions are not made in a vacuum. They are made in the context of a particular business strategy, skills and experience, a particular organizational culture, and a particular set of technology and data capabilities. Most companies focus on just two elements -- technology and data -- or none at all," observes Davenport, Harris, DeLong, and Jacobson [13]. No group can really escape culture, as "creating shared rules, even if they are never written down, is a precondition for group survival" [25]. Davenport, DeLong, and Beers [12] further recognize that a successful technology project is linked to a favorable corporate culture through eight key factors:

- $\quad$ Economic performance or industry value

- Technical, organizational infrastructure

- Standard, flexible knowledge structure

- Knowledge-friendly culture

- Clear purpose and language

- Change in motivational practices

- Multiple channels for knowledge transfer

- $\quad$ Senior management support 
Figure 2 illustrates Davenport's depiction of a knowledge-based project's strategy; however, for the purposes of this paper, the model clearly shows that within the cone's base the attributes of 'organization and culture' have equal standing with 'technology and data,' providing a solid foundation for a successful project.



Figure 2. A Model for Building an Analytic Capability, (C) Davenport, et al. [13]

\section{THE LEADER}

Today most organizations ensure that prudent business decisions are made by seasoned highly educated professionals, led by C-Level corporate executives known as the Chief Information Officer (CIO) or the Chief Technology Officer (CTO). In this paper, the acronym CIO is used to represent the roles of all senior technology leaders. CIOs use Information Technology (IT) and Systems (IS) to formulate business strategies and intelligence, maintain a competitive edge, and create and enable lasting value for their companies. Their decisions to procure new technologies, upgrade existing products, or merely maintain the status quo critically impact business strategies for years to come, a heavy mantel of responsibility resting upon a single individual or team.

Eckerson [19] argues that organizations succeed not only because of specific technology, but because of the soft skills of leadership, communication, planning, and interpersonal relationships. Tseng [52] notes that without a champion to nurture the desired path, organizational culture can present a major barrier to any worthy project. Equally convinced, Gonzales [23] avers that strong leadership is essential to achieve technology maturity. During entity-formation leaders emerge to create the culture, but in the more mature stages of an organization the culture creates the leaders, as those managers that fit the mold are typically appointed to the top positions [40]. Schein [39] warns that a dangerous narrow-focused cultural awareness exists because "these shared tacit assumptions are now an unconscious determinant of most of what goes on in an organization."

A prudent $\mathrm{CIO}$ manages this effort like a formal project for an external customer. When developing strategies, pondering new purchases, or solving problems, CIOs rely upon the experience and recommendations from a team of professionals, represented by multiple disciplines such as IT/IS, contracts/legal, accounting, procurement, human resources, marketing/communications, engineering/manufacturing, business development, as introducing a new tech product, process, or system impacts every department and subculture in the company in a primary, secondary, or tertiary capacity. Additionally, the CIO secures executive level sponsorship and support to ensure a high level of confidence and trust in his/her authority and decision-making powers. Executive management support to identify a corporate sponsor, will enable a champion to "define the vision, be an activist, and communicate a unified message" [49] paving the way for a manageable organizational cultural change in concert with IT/IS goals.

\section{THE MESSAGE}

The CIO has a personal responsibility to set forth his/her vision for the strategy and adoption of the technology. As the leader of change, the CIO's delivery system or medium is just as important as the message itself [32]. The organizational culture expects the leader to be communicative, inspirational, and reassuring. Becker [2004] proffers 
that interviews and facilitated sessions are the best way to solicit user feedback and to create face-to-face bonds, as surveys cannot read the culture. Trembly [51] observes that, "Tech products do great things but they also make people nervous. One way of encouraging participation is to regularly communicate the status and progress of the project to everyone concerned."

As it is inherently human to resist change, the quality and delivery of the announcement must not minimize the impact or lessen the severity of the reaction, because the trauma will be more severe when it is realized that the truth has been withheld. And presenting a change as temporary, knowing that it will not be, is a manipulative practice that seldom ends well for the communicator. The announcement of the change must be comprehensive, factual, and specific [9]. Lurking about is the dangerous illusion that everyone understands each other, but rarely does the leader investigate the culture in advance to ascertain if the context is high or low [24], and secure feedback to ensure the meanings and intent are fully understood. Therefore, the audience must be empowered with the truth and a mission to succeed in order to embrace and implement change effectively and to accept the new technology.

Cultural awareness of potential obstacles by mandating clear and cogent communication will mitigate barriers of mistrust before they become hurdles and detriments to technology implementation or modifications to the system. Davenport, et al. [13] suggest that, "The most sophisticated analyses in the world are worthless if findings cannot be communicated to decision-makers in ways that will encourage their use."

\section{THE PROJECT TEAM}

Sometimes the most brilliant, senior, experienced, educated, or technologically savvy individuals do not make the best team members. But leaders, like coaches, can orient the team's culture through actions, symbols, and values to reframe the meanings of team membership toward common goals and objectives.

\section{The Project Manager}

One of the most critical decisions made by the CIO is the appointment of a talented and responsible individual to execute the project's vision and strategy. A dedicated Project Manager (PM) can fulfill this role by serving as a facilitator and liaison to the CIO, keeping the technology leader informed and the team focused and on-task. PM skills involve balancing technology, people, and process management because: "Failure in any area means failure of the project. Technology is usually the scapegoat, but the tech is proven. It's really about culture change" [51].

\section{The Team}

The PM's recommendations for the prudent selection of team members are critical to ensure the likelihood of esprit de corps, a shared vision, strong work ethic, and cultural understanding. End-users should also participate as team members and beta-testers as their contributions to the overall product development and effectiveness will be invaluable. Routine conversations between the tech team and the user community about the ability of the IT environment to meet their needs will encourage productive input, save re-work, and course-corrections later. Becker [4] recommends that: "The most important aspect is meeting with the user community to solicit feedback."

\section{The Project Plan}

The PM, with input from the Team, develops a Project Plan identifying specific elements such as a work scope, performance period, milestones, budget, schedule, key personnel, workspace, meetings, reports, assignments, and deliverables to cover all the tasks. Definitive decisions are made, such as the identification of contractors or consultants, whether new products will be licensed or existing products replaced, enhanced, modified, or upgraded. Tasks are then entered into and monitored within a traditional work breakdown structure. As with any formalized project, all costs (direct and indirect) are segregated, identified in a code of accounts, and tracked within the organization's cost accounting system. The Project Plan cannot merely induce technology change, but must also seek alignment with the existing organizational culture [4]. 


\section{Outsourcing}

Should the CIO and Team determine that technology products or services are to be outsourced; the market research and solicitation process begins immediately. Bidders lists are created, solicitations developed, and sources sought. The results of a competitive or sole source opportunity have a substantial impact on the cost and schedule of the technology acquisition and its implementation. Types of procurements and resultant contracts also play major roles, such as advisory consulting, service contracting, training agreements, product and equipment purchase or lease decisions, license or development decisions, and open or closed source code considerations. Comparing life-cycle costs to short-term initiatives, acquiring or merging with another company, adopting another's IT strategy, or considering reductions in force, all have significant social-cultural impacts on the employees. Capacity of the organization to produce under these constraints and empowering the team to recommend and participate in strategic decisions will teach and encourage employees to lead, resulting in enthusiastic pro-activity to embrace change [2].

\section{THE RIGHT TECHNOLOGY}

The availability of new technology is as vast as the reasons for selecting new products and services. Turkle [53] suggests that "technology is seductive when what it offers meets our human vulnerabilities." Technology and culture tend to evoke dramatically different connotations, systems of meaning, experiences, and worldviews. Many believe that: "Technology is clean, powerful, exciting and a magical key to prosperity" [3]. As naïve as this statement may be, some aver there are no problems that cannot be solved without some form of technology. Technophiles [35] and early adopters [8] argue that technology represents a necessary upheaval, innovation, and creative destruction to the permanence and stability of organizational, societal, and national culture; while Technophobes and late adopters are generally content with the status quo and resist change until its inevitability. Although technology doesn't solve every problem of its own accord, Pariser [34] argues that: "Technodeterminists like to suggest that technology is inherently good when people make it do good things and use it in good ways."

Selecting new technologies are of paramount importance, taking an enormous amount of research, planning, and preparation to accomplish. Since all enterprises are unique, the traditional information systems Technology Acceptance Model [1,14] where perceived usefulness and ease of use are of primary benefit to end-users and their sponsors is only one factor to analyze. Today's $21^{\text {st }}$ century CIO also seriously considers the influence and impact of the organizational culture among a myriad of technical and social issues under a holistic system. When the members of a mature organizational culture recognize that the mission of the new technology aligns with its own workplace goals and objectives, barriers are lowered and cultural acceptance takes hold (Figure 1).

Prior to selecting the right product, process, or service, today's CIO weighs the risks and threats, such as costs, schedule, down-time, resources, safety and security of the company against the future benefits, rewards, competitive advantage, increased workforce, and gaining potential market share. An important function of a CIO is to act as steward of the company's technology purse, continually managing the serviceability and value of the enterprise, and evaluating all the technology costs that will culminate in the overall life cycle before replacement. But determining the potential Return on Investment (ROI) is not enough if the organizational culture resists the new technology and the members will not use the new system.

\section{THE SYSTEM DESIGN}

When the CIO, in concert with executive management, determines that the organization is ready for an IT/IS change, it is important that the new or changed system is closely aligned with its original business goals and organizational culture, or adjusted to fit the revised corporate strategy. The existing system may not need to be completely abandoned and should be examined first for opportunities for enhancement or upgrade. A successful organization leverages the strengths of useful systems and its culture by synergistically incorporating the existing technology into new products and services whenever possible.

This process will also serve as a point of reference (comfort zone) to the organization's employees who may be resistant to change or wary of learning and using new technology products or systems. For example, employees are creative, innovative and impatient, and if they cannot access an information system, or are frustrated at the rate of response, or merely do not know how or what to do, they often implement technical workarounds. Akin to this view, 
Becker [4] offers that: "One of the more troubling IT maladies is the business acceptance disorder. In layperson's terms, the business community isn't using the technology." Identifying and diagnosing the symptoms early, soliciting user feedback immediately, embracing and rectifying the issues, and providing additional education or training if warranted will also secure users buy-in.

No less important, technologists understand the construct of agility and its value during project design and implementation. Agility copes with and overcomes ever-changing and evolving organizational events through maneuverability, flexibility, iteration, and the ability to rapidly adapt to dynamic scope and environmental changes and course corrections [30]. Agile technology development equally applies to the agility required of people, processes, and culture within a well-defined rapid-response fast-paced organizational setting.

Building flexibility into the system at milestones or cost points will also serve as interim review points where a midcourse correction or change will be the easiest to implement with the least negative impact to cost, schedule, or personnel. Although creative ideas from team members are welcome, the PM needs to prioritize all primary tasks to maintain the spirit of the original goals and objectives, thereby avoiding complexities (bells and whistles) that may exceed the capabilities of the enterprise architectural capacity, the allotted funding, the schedule, and the personnel. Wise CIOs will also review notes and lessons-learned from existing system implementations or related past projects to ensure that prior technical and cultural errors and missteps are not inadvertently repeated.

\section{THE PROCESS - CHECKS \& BALANCES}

Ever cognizant of the schedule, budget, and management of course corrections, the PM requires business management tools to monitor a tech project's progress. Organizational enterprise systems incorporate specific software products to manage a project, but checks and balances are managed by human processes and systems. Professionals advocate the concept of the Balanced Scorecard as a team's map of key objectives and themes [43], Earned Value Management (EVM) for its metrics to analyze the functional tasks of planning, budgeting, and discipline [31], and the "Strength, Weaknesses, Opportunities, and Threats (SWOT)" analysis [26] as invaluable guidance toward an evaluation of a company's critical elements comparing the risks and rewards of each strategic quadrant. When organizational culture is also incorporated as a key project element, any method can provide valuable assistance to the $\mathrm{CIO}$ and Team when determining the correct technical strategic path and monitoring the cultural condition, integral to measuring and reporting incremental successes to the organization. Culture is deep, unconscious, extensive, and stable. Culture is a tacit mechanism of control [29] and it cannot be taken lightly. "If you do not manage culture, it will manage you" [39].

The decision when to implement new technology is just as critical as the selection of the technology itself. Traditional strategic business planning is generally oriented to three to five year cycles [43], but due to the rapid change and high risk model of implementation, the CIO must be flexible enough to respond with planning adjustments as often as quarterly, semi-annually, or as needs dictate. Cost considerations, such as scheduling, budget, procurement, contract negotiations, subcontractors and consultants are all critical to success. The coordination and delivery of material and equipment, build-outs of sites, computer rooms, storage facilities, servers, purchase of ancillary equipment, development of user manuals and standard operating procedures and training all require a facilitator assigned to manage and monitor each process. Equally critical is the human factor, ensuring that key personnel are in place for implementation, transitions, turn-over of responsibilities, and eventual day-to-day operations. Managing change, resolving conflicts, and performing what is promised when it is due will garner respect and win followers during the roll-out [9].

\section{THE ROLL-OUT}

Many considerations must be addressed when the technology roll-out is planned and questions abound. Should the CIO run parallel products or systems for 30,60 , or 90 days, six months, one year, or should a cut-off date be established with a complete and abrupt switch-over to the new technology? Should the CIO plan and operate a short Alpha Test in-house and a prolonged Beta Test with a pilot or control group of employees, or the reverse? Does the enterprise plan radically turn-on the new system for the entire company concurrently, or shall it be managed incrementally in departmental or regional (geographic time zone) phases so that customer support is constantly maintained and mid-stage adjustments or corrections can be implemented without impacting everyone? How shall the employees and the public be notified and when? Will the training be performed in-house or by consultants? Any 
of these events trigger changes to way "we do things around here" [25] and disruptions to the organizational culture, manifesting in feelings of insecurity represented by panic of the unknown, failure to learn new skills, and in some dire cases, fear of loss of employment. The culture will be tested [20,21], and the CIO must have a mitigation plan in place and implemented before culture shock can paralyze the organization [33].

The concerns of the clients must also be considered, such as running parallel systems of soon to be replaced or obsolete technology to maintain performance, revenue streams, and meet external and internal compliance thresholds while mitigating customer fears and ensuring consistent support and satisfaction. When determining a cut-off date to cross-over to the new technology, the company must anticipate planning for adequate job coverage when employees attend training. Equally important will be handling slower work performance while employees adjust to a learning curve. And the CIO must decide whether or not (and for how long) to maintain a legacy technology as a back-up system and if adequate funding and manpower are available to support this extra effort.

A knowledgeable CIO knows the exact levels of technology acceptance readiness for the majority of the organizational subcultures and can readily identify them as: Innovators, Early Adopters, Early Majority, Late Majority, and Laggards [37]. Unless the CIO and the project team adequately prepare employees for this new technology, culture shock [33] may ensue. Culture shock is caused by the anxiety, stress, frustration, powerlessness and resentfulness that result from losing all familiar signs and symbols of daily practices and routines. The construct implies that the unexpected experience of change may result in negative feelings about one's own culture [21]. Mitigating culture shock through recovery and acceptance is the key to change management and conflict resolution. However, since culture shock can also result from the speed of technological innovation, it may become a favorable transitional experience resulting in the adoption of new values, attitudes, and behavior patterns [20].

Thornthwaite [48] argues that continuous education of management, staff, and users is essential to maintain corporate commitment, buy-into the culture change, and to convince the stakeholders of the value and purpose of the new technology. Furthermore, "for knowledge-creation and decision-making, the organization must have a learning culture" [46]; and the technology leader must thoroughly understand the culture and its subcultures.

At times it is necessary for management to modify the organizational culture by establishing incentives to motivate and encourage employees' buy-in to the new or changed system. Establishing appropriate rewards for employees who lead the way by utilizing the system can become an important organizational ritual or tradition. Recognitions, such as gift cards, awards, bonuses, contests, and favorable performance reviews encourage effective long-term behavior, and should tie-in with the compensation structure [12, 27]. Tiwana [49] observes that, "Employees are not like troops, they are like volunteers. Encouraging use and gaining support requires new reward structures that motivate employees to use the system and contribute to its adoption."

\section{DISCUSSION}

Technology and culture tend to evoke dramatically different connotations, systems of meaning, experiences, and worldviews. The socio-technical theory [6] describes the interaction between people and technology in the workplace and social informatics [28] provides the tools of the interface. In the $21^{\text {st }}$ century, technology and culture do not lead separate lives, but are implicitly and explicitly intimately connected and linked by communities of practice, meanings, signs, cues, and coded and decoded language. A successful CIO knows that sharing a common language is not the same as understanding the people. Based upon this philosophical understanding, we conclude that: H1. Organizational culture influences the success or failure of technology adoption within the workplace.

Within human communities, trust is a common construct based upon familial kinship values and a shared topology of stable relationships and identities. Introducing a new technology, changing our practices and rituals, and disrupting our rhythms are constantly tested in the Digital Age. We learned that organizational culture only fails when it cannot accept and thrive upon the increasing capabilities of technology. And a strong cultural foundation built upon an organization's common goals of innovation and collaboration can withstand the culture shock of new technology, survive and even thrive. Based upon these collective findings, we conclude that: H2. Understanding and incorporating organizational culture into the technology implementation favorably increases its successful adoption.

When a CIO fully understands the social-cultural environment, continuously communicates a reassuring clear and cogent message, carefully selects a project team, plans and implements the right technology that aligns with the core 
values and mission of the enterprise, and rolls out the program on-time and within budget, there is good chance that the organizational culture will accept and eventually embrace the change. No longer considered merely a traditional service group embedded in a "departmental silo, the business of the IT/IS organization is technology, and the business of the CIO is the business of the entire enterprise" [43].

\section{CONCLUSIONS}

Based upon a secondary review of technology adoption literature and philosophies from cultural theorists, social scientists, and business management experts, we opine that organizational culture has a great deal more influence and impact on technology adoption than traditionally considered. Therefore, we affirmatively conclude that the following hypotheses are upheld by the theories and independent research of the cited subject matter experts: H1. Organizational culture influences the success or failure of technology adoption in the workplace; and, H2. Understanding and incorporating the organizational culture into the technology implementation process favorably increases successful technology adoption.

The CIO must thoroughly understand the innovative technology in concert with the organizational culture and have the ability to convince others of its value and benefits. It is a heady experience and upon success the rewards and accolades are great, but the miscalculations that negatively impact so very many can be dire. The effective CIO stays true to the mission of the organization, its core values and its culture, and embraces technology change for the better. Carton [9] captures the essence of this eternal challenge with this assertion:

Successful changes are a continuous process. In the field of information systems, it is often promised that new software or computer systems will give a bit of a break. This is never true, and the break is always shortlived. Far better to experience change as a process and forget the concept of permanency. Each change follows and precedes a change and is never isolated [p.80].

Long ago and still true today, philosophers and theorists understood the insatiable thirst of the human race for constant improvement and change through technological innovation. We argue that the infinite siren to improve and enhance information systems through technology adoption requires an equal and concurrent commitment to understand and embrace the social-cultural organizational environment; and then incorporate its profound influence as a strategic advantage.

\section{REFERENCES}

1. Bagozzi, R. (2007). The legacy of the technology acceptance model and a proposal for a paradigm shift. Journal of the Association for Information Systems, 8(4), 244-245.

2. Balasco, J., \& Stayer, R. (1993). Flight of the buffalo: Learning to let employees lead. New York: Warner Books.

3. Batteau, A. (2010]. Technology and culture. Long Grove, IL: Waveland Press.

4. Becker, B. (2004). Boosting business acceptance. In R. Kimball, \& M. Ross (Eds.), The Kimball Book Reader (pp. 667-670). Indianapolis: Wiley Publishing.

5. Beniger, J. (1986). The control revolution: Technological and economic origins of the information society. Cambridge: Harvard University Press.

6. Bostrom, R., \& Heinen, J. (1977). MIS problems/failures: Sociotechnical perspective. MIS Quarterly, 1(3), 17-32.

7. Breslin, M. (2004). Data warehousing battle of the giants: Comparing the Kimball \& Inmon models. Business Intelligence Journal, 9(1), 6-20.

8. Carr, N. (2003, May). IT doesn't matter. Harvard Business Review Onpoint, 3566, 41-49.

9. Carton, G. (2008). In praise of change ( $2^{\text {nd }}$ ed.). Paris: Pearson Village Mondial.

10. Christensen, C. (1997). The innovator's dilemma: When new technologies cause great firms to fail. Boston: Harvard Business School Press.

11. Cooper, R. (1994). The inertial impact of culture on IT implementation. Information Management, 27, 17-31.

12. Davenport, T., DeLong, D., \& Beers, M. (1998). Successful knowledge management projects. Sloan Management Review, 39(2), 43-57.

13. Davenport, T., Harris, J., DeLong, D., \& Jacobson, A. (2001). Data to knowledge to results: Building an analytic capability. California Management Review, 43(2), 117-138.

14. Davis, F. (1989). Perceived usefulness, perceived ease of use, and user acceptance of information technology. MIS Quarterly, 13(3), 319-340. 
15. Deal, T., \& Kennedy, A. (1999). The new corporate cultures: Revitalizing the workplace after downsizing, mergers, and reengineering. Cambridge: Perseus Publishing.

16. Deal, T., \& Kennedy, A. (2000). Corporate cultures: Rites and rituals. New York: Basic Books.

17. Debons, A. (2008). Information science 101. Lanham, MD: Scarecrow Press.

18. Drucker, P. F. (1959). Landmarks of tomorrow ( $1^{\text {st }}$ ed.). New York: Harper.

19. Eckerson, W. (2003). Smart companies in the $21^{\text {st }}$ century: The secrets of creating business intelligence solutions. TDWI Website. Retrieved August 11, 2003 from: http://www.dw-institute.com/research/

20. Furnham, A. (1997). Corporate culture shock: Surviving organizational change. Singapore: Times Books Int'l.

21. Furnham, A., \& Bochner, S. (1986). Culture shock: Psychological reactions to unfamiliar environments. New York: Methuen \& Co.

22. Geertz, C. (1973). The interpretation of cultures. New York: Basic Books.

23. Gonzales, M. (2011). Success factors for business intelligence and data warehousing maturity. Business Intelligence Journal, 16(1), 22-29.

24. Hall, E. T. (1977). Beyond culture. New York: Anchor Books.

25. Hofstede, G., Hofstede, G.J., \& Minkov, M. (2010). Cultures and organizations: Software of the mind. New York: McGraw-Hill.

26. Humphrey, A. (Dec. 2005). Stanford Research Institute (SRI) Newsletter (pp. 7-8). Menlo Park, CA.

27. Hurley, R. (2002). Putting people into organizational learning. Journal of Business Marketing, 17(4), $270-281$.

28. Kling, R. (2007). What is social informatics and why does it matter? The Information Society, 23(4), $205-220$.

29. Kunda, G. (2006). Engineering culture: Control and commitment in a high-tech corporation ( $\left.2^{\text {nd }} \mathrm{ed}.\right)$. Philadelphia: Temple University Press.

30. Larman, C. (2004). Agile and iterative development. Boston: Addison-Wesley.

31. Marshall, R. (2007). The contribution of earned value management to project success: A quantitative statistics approach. Journal of Contract Management, I, 21-33.

32. McLuhan, M., \& Lapham, L. (1964). Understanding media: The extensions of man. Cambridge: MIT Press.

33. Oberg, K. (1960). Culture shock: Adjustment to new cultural environments. Practical Anthropology, 7, $177-182$.

34. Pariser, E. (2011). The filter bubble: How the new personalized web is changing what we read and how we think. New York: Penguin Books.

35. Postman, N. (1993). Technopoly: The surrender of culture to technology. New York: Vintage Books.

36. Procter, M. (1993). Analyzing Another's Data. In N. Gilbert (Ed.). Researching Social Life. London: Sage.

37. Rogers, E. (2003). Diffusion of innovations ( $5^{\text {th }}$ ed.). New York: Free Press.

38. Sandelowski, M. (1997). Enhancing the utility of qualitative research. Nursing Outlook, 45(3), 125-32.

39. Schein, E. (2009). The corporate culture survival guide ( $2^{\text {nd }}$ ed.). San Francisco: Jossey-Bass.

40. Schein, E. (2010). Organizational culture and leadership (4 ${ }^{\text {th }}$ ed.). San Francisco: Jossey-Bass.

41. Shirky, C. (2008). Here comes everybody. New York: Penguin Press.

42. Standage, T. (1998). Victorian internet: Story of nineteenth century's on-line pioneers. New York: Walker Pub.

43. Stenzel, J. (2007). CIO best practices: Enabling strategic value with IT ( $2^{\text {nd }}$ ed.). Hoboken: Wiley \& Sons.

44. Štok, Z., Markič, M., Bertoncelj, A., \& Meško, M. (2010). Elements of organizational culture leading to business excellence. Zb.rad.Ekon.fak.Rij., 28(2), 303-318.

45. Szabo, V., \& Strang, V. (1997). Secondary analysis of QL data. Advances in Nursing Science, 20(2), 66-74.

46. Sun, P. (2010). Five knowledge organizational themes. Journal of Knowledge Management, 14(4), $507-523$.

47. Thorne, S. (1994). Secondary Analysis in Qualitative Research: Issues and implications. In J. M. Morse (Ed.). Critical Issues in Qualitative Research Methods. London: Sage.

48. Thornthwaite, W. (2007). Educate management to sustain DW/BI success. In R. Kimball, \& M. Ross (Eds.). The Kimball Book Reader (pp. 670-673). Indianapolis: Wiley Publishing.

49. Tiwana, A. (2002). The knowledge management toolkit: Orchestrating IT, strategy, and knowledge platforms $\left(2^{\text {nd }}\right.$ ed.). Upper Saddle River, NJ: Prentice Hall.

50. Toffler, A. (1981). The third wave. New York: Bantam Books.

51. Trembly, A. (2001). Technology not blamed for data warehouse failures. National Underwriter, 105(45), 32-41.

52. Tseng, S-M. (2010). The effects of hierarchical culture on knowledge management processes. Management Research Review, 33(8), 827-839.

53. Turkle, S. (2011). Alone together: Why we expect more from technology and less from each other. New York: Basic Books.

54. Zheng, W., Yang, B., \& McLean, G. (2010). Linking organizational culture, structure, strategy and effectiveness. Journal of Business Research, 63, 763-771. 